\title{
LA PROFESIONALIZACIÓN DOCENTE EN PERSPECTIVA CRÍTICO-GENEALÓGICA. EL CASO ESPAÑOL ${ }^{i}$
}

\author{
A PROFISSIONALIZAÇÃO DOCENTE NA PERSPECTIVA CRÍTICO- \\ GENEALÓGICA. O CASO ESPANHOL
}

\author{
Juan Mainer Baqué \\ Federación "Icaria" (Fedicaria)
}

\section{Resumen}

En este trabajo se trata de esbozar algunas ideas sobre la construcción del oficio docente, desde una perspectiva crítico-genealógica, que nos permitan situar históricamente los actuales discursos y prácticas, de neta raigambre neoliberal, sobre la formación del profesorado, así como los supuestos nuevos perfiles profesionales que se postulan y pretenden, en particular para la educación secundaria en España, en el marco de las políticas educativas del totalcapitalismo.

Palabras clave: Profesionalización docente. Perspectiva crítico-genealógica. Didáctica Crítica. Tecnoburocracia. Totalcapitalismo.

\section{Resumo}

Neste trabalho, tentamos delinear algumas ideias sobre a construção da profissão docente, desde uma perspectiva crítico-genealógica, o que nos permite situar historicamente os discursos e práticas atuais, com claras raízes neoliberais, sobre a formação de professores, assim como os supostos novos perfis profissionais que são postulados e buscados, particularmente para o ensino secundário na Espanha, no marco das políticas educativas do "totalcapitalismo". 


\title{
LA PROFESIONALIZACIÓN DOCENTE EN PERSPECTIVA CRÍTICO- \\ GENEALÓGICA. EL CASO ESPAÑOL
}

Palavras-chave: Profissionalização docente. Perspectiva Crítico-Genealógica. Didática Crítica. Tecnoburocracia. Totalcapitalismo.

\author{
"Un problema verdadero es mucho más difícil de buscar y \\ construir que una justa respuesta, para lo cual —nunca \\ permanentemente satisfactoria - la pertinencia de aquel es la \\ primera y más importante condición."
}

Carlos Lerena (1983).

Aunque rara vez lo exprese en estos términos, sostiene el pensamiento pedagógico común que hay dos escuelas: la existente y la posible. Y para hacer valer tal precepto, forja una ilusión consistente en separar la escuela - máquina o aparato ciego - de sus propietarios, los intelectuales, en el ingenuo convencimiento de que dotando a estos de buen conocimiento, disposición, métodos y voluntad adecuados, estarán en condiciones de conquistar la máquina, domeñarla al servicio de las metas más sublimes y fundar la "otra", la posible. La formación de los docentes comparece así como una herramienta imprescindible al servicio de la sempiterna utopía escolar (la que sea). En esta visión hegemónica y profundamente idealista de la escuela y del campo de la educación todo resulta obvio — según el Diccionario de la Real Academia Española, obvio es lo que se encuentra o pone delante de los ojos, que es muy claro o que no ofrece dificultad-. Así, obvio parece el hecho de que la docencia sea un oficio con una especificidad propia y que requiere de quien lo ejerce una preparación adecuada; obvio, es afirmar que para enseñar algo en la escuela se precisan conocimientos, pero también cierta habilidad para transmitirlos; obvio es, en fin, que ambas dimensiones se integren en los planes de estudio destinados a la construcción de los sujetos docentes. Si las cosas fueran tan claras, no merecería la pena seguir escribiendo: bastaría con dejar a los expertos el diseño, como ahora se dice, del mejor iter formativo y esperar los brotes verdes. Sin embargo, algo me dice que las cosas no son así. El problema es que, una vez más, las cosas no son lo que parecen: en primer lugar porque no hay "dos escuelas" y en segundo lugar porque los intelectuales, lejos de ser los "amos" de la escuela, indefectiblemente, "son" la escuela y, dicho con toda crudeza, no pueden conquistar nada porque forman parte, inextricablemente, de ella.

De ahí que cuando del oficio docente hablamos, convenga, como aconseja el texto que encabeza estas líneas, delimitar bien el problema al que nos enfrentamos y para ello es buena

\begin{tabular}{l|l} 
Revista RBBA & Revista Binacional Brasil Argentina
\end{tabular} 
cosa dejarse de obviedades y cantos de sirena y comenzar por reparar en el terreno de juego llamándolo por su nombre - la institución escolar de la era del capitalismo—, en sus gestores y actores, en su dimensión histórica y espacio-temporal. En este sentido, digámoslo de una vez: el oficio docente y los sujetos que lo profesan no tienen esencia, tienen historia. Es decir: son el producto de una determinada situación histórica, aunque, performativamente, contribuyan también a forjar y reproducir esa misma realidad social que al mismo tiempo les construye. De modo que, en las páginas que siguen, trataré de esbozar algunas ideas sobre la construcción del oficio docente desde una perspectiva genealógica que nos permitan situar históricamente los actuales discursos y prácticas sobre la formación del profesorado así como los supuestos nuevos perfiles profesionales que se postulan y pretenden, en particular para la educación secundaria.

El proceso de profesionalización de un docente puede y debe contemplarse como una totalidad constituida por tres dimensiones que se suceden en el tiempo profesional y que marcan de forma indeleble su ethos corporativo y su habitus profesional: la dotación de conocimientos antes de la práctica, el acceso a la docencia, y la capacitación en el ejercicio activo, constituyen tres momentos y tres caras, constitutivas y constituyentes, de lo que podríamos llamar la arquitectura profesional docente. Esto ha sido así, con mayor o menor intensidad, desde la erección de los sistemas educativos nacionales a lo largo de la primera mitad del siglo XIX de la mano de las revoluciones liberales burguesas. En todo caso, estamos hablando de una profesión que, dadas sus peculiares características, siempre fue relegada a la categoría de las "semiprofesiones"..., una especie de subconjunto profesional de perfiles muy difusos y epistemológicamente débiles. Así pues, es obligado situar la profesión docente y los saberes que le son inherentes - "eso" que desde no hace mucho, en España desde la década de los años 60 del siglo pasado, viene denominándose "ciencias de la educación"—, dentro de los estratos sociales especializados en la producción del campo simbólico y en la reproducción cultural.

Sería interesante recordar cómo nos socializamos realmente con la profesión. La forja del sujeto docente se inicia, inexorablemente y sin pretenderlo, en nuestra etapa de discentes, cuando todavía somos alumnos. Es allí donde, de modo infraconsciente, adquirimos la certeza de que toda relación pedagógica es, por encima de todo, una relación de poder. La mayor parte de nuestro trabajo después, ya como profesores, nunca es del todo ajena a la \begin{tabular}{l|l} 
Revista RBBA & Revista Binacional Brasil Argentina
\end{tabular} 
LA PROFESIONALIZACIÓN DOCENTE EN PERSPECTIVA CRÍTICO-

GENEALÓGICA. EL CASO ESPAÑOL

reproducción y contextualización de aquellas pautas de organización y control del tiempo y el espacio en las que fuimos instruidos y que, velis nolis, terminan por ser las que mejor han venido respondiendo a las necesidades y funciones de la escolarización; de ayer y de hoy estructuras crono-espaciales, rutinas y disposiciones cotidianas, prácticas examinatorias, etc.- - Estoy convencido de que para entender algo de lo que realmente sucede en el interior de nuestras aulas, el camino no es concebir al docente como una individualidad racional capaz de gobernar su vida profesional de manera autónoma siguiendo el dictado de su conciencia y el de sus supuestos conocimientos científico-pedagógicos adquiridos tras largos periodos de estudio y reflexión. Con demasiada frecuencia el profesor, como sujeto social, no actúa según piensa o dice pensar; de nuevo el malogrado sociólogo de la educación Carlos Lerena (1986), siguiendo los pasos de Foucault y Bourdieu, acertó a expresarlo con suma claridad: "lo que los educadores, como norma, dicen que hacen, lo que creen estar haciendo y por qué creen hacerlo, etc., constituye un obstáculo que impide profundizar en el conocimiento de lo que realmente hacen y del significado de lo que hacen".

La falacia del rampante idealismo del discurso pedagógico — da igual que provenga del apostolado rousseaniano y su empalagoso discipulazgo, como del más obsesivo ciencismo o tecnicismo, hoy tan en boga- consiste en ocultar que el sujeto docente es, fundamentalmente, un actor que, condicionado por estructuras estructurantes, se limita a interpretar un guión prescrito según prácticas discursivas naturalizadas y codificadas y emanadas de coriáceas y duraderas culturas profesionales. Es en el interior de estas últimas, mucho más que en la supuesta asimilación de conocimientos transmitidos por los científicos y burócratas de la educación - llámense académicos, inspectores, o, más recientemente, expertos y líderes de la innovación educativa-, donde se configura y dota de sentido nuestro modo de ser y de estar en el espacio escolar. La alta y la baja pedagogías, por expresar de un modo sencillo la dualidad entre teoría pedagógica y práctica escolar, casi nunca se encuentran y con frecuencia ni siquiera dialogan entre sí, pues los contextos de producción, las finalidades y las lógicas de una y de otra son de naturaleza muy distinta. Precisamente, como ya se apuntó, corresponde a la alta pedagogía la principalísima función de nutrir y mantener viva la ilusoria promesa del cambio escolar, pero las relaciones que se establecen entre tales teorizaciones y las prácticas de enseñanza distan mucho de ser directas y cristalinas; más bien han sido siempre oscuras, contradictorias e imprevisibles como viene poniendo de manifiesto la historiografía de la educación dentro y fuera de España ${ }^{\text {ii }}$.

Revista RBBA $\mid$ Revista Binacional Brasil Argentina 
Consecuentemente, la formación de un docente debería comenzar por desaprender lo aprendido, por desnaturalizar lo dado, por entender y desentrañar, en definitiva, las claves de esos coriáceos y duraderos códigos socio-profesionales que nutren y guían nuestro quehacer en la escuela. Todo ello, en mi opinión, constituye una premisa sine qua non para poder impugnarlos y, por eso, ahí residiría el núcleo performativo de una posible didáctica críticaii . El docente verdaderamente "formado" sería aquel capaz de pensar sobre y contra sí mismo, contra su práctica, contra su posición en el juego de relaciones de poder que se establecen dentro y fuera del aula y contra la racionalidad instrumental y tecnocrática de la pedagogía institucional, en tanto que saber-poder, que legitima su condición de mero operario-aplicador de diseños ajenos. Con razón, E. Durkheim advertía a sus alumnos, que una historia de la enseñanza y de la profesión de enseñar estaba llamada a ser, necesariamente, "la mejor de las pedagogías". Y, con no menos razón, venimos afirmando en Fedicaria que pensar históricamente los problemas que nos afectan (afrontar el ejercicio de la docencia desde una perspectiva crítico-genealógica), constituye en realidad practicar una no menos necesaria ontología de nosotros mismos.

\section{La profesionalización de los docentes: una perspectiva crítico-genealógica}

Históricamente, desde que la segunda enseñanza fuera concebida a imagen y semejanza de los estudios universitarios desde mediados del siglo XIX, se ha sobrentendido que el conocimiento especializado del que es portador el profesorado de secundaria contenía en sí mismo las claves de su propia difusión. Así, la formación inicial, los sistemas de acceso y la propia actualización permanente en activo se han venido ajustando, hasta fechas relativamente recientes, a esta concepción duradera y tácita. Por el contrario, la formación del profesorado de enseñanza primaria siempre ha contado con la suposición implícita de tratarse de un oficio artesanal y eminentemente práctico, referido estrictamente al trato con la infancia y no a la posesión de un saber específico, que había de adquirirse en un centro especializado en el arte de enseñar. Los cambios de sentido en la formación del profesorado secundario, menos llamativos en la del magisterio, constituyen, por tanto, una construcción social y responden a una profunda y relativamente reciente reconversión de su función en el sistema educativo. Reconversión que coincide con el despliegue del modo de educación tecnocrático de masas $^{\mathrm{iv}}$ que, con unos veinte años de retraso respecto al resto de países del occidente 
LA PROFESIONALIZACIÓN DOCENTE EN PERSPECTIVA CRÍTICO-

GENEALÓGICA. EL CASO ESPAÑOL

europeo, tuvo lugar en España, aún en plena dictadura, durante la década de los años sesenta del siglo XX y que adquirió carta de naturaleza jurídica con la Ley General de Educación de 1970; marco legislativo que vino a sustituir a la vetusta Ley Moyano de 1857, vigente durante más de un siglo.

El sistema de reclutamiento y formación del profesorado de primaria y secundaria se realizó en España durante el siglo XIX de forma coetánea al proceso de construcción del Estado liberal. Durante el reinado de Isabel II (1833-1868) se instauraron en cada provincia las Escuelas Normales para la formación de maestros y las Facultades de Ciencias y Letras para los licenciados encargados de impartir clases en el Bachillerato. Los planes de estudios de Normales y Facultades nada tenía que ver entre sí y, en puridad, las escuelas de formación de maestros fueron, durante el modo de educación tradicional-elitista, una modalidad de enseñanza media y una opción de formación profesional para los hijos del campesinado y de los estratos bajos de una naciente mesocracia. Así como la definición de los cuerpos docentes secundarios y universitarios y su forma de acceso mediante oposición fue reglamentada con prontitud, la condición de maestro (y sobre todo de maestra) se consolidó burocráticamente mucho más tarde, a principios del siglo XX —durante mucho tiempo para ejercer en los núcleos rurales no solía reclamarse titulación alguna-.

En términos generales, el magisterio constituyó siempre un subproletariado docente con bajas retribuciones y mínima especialización: un oficio, en suma, vinculado a la práctica. Por el contrario, los cuerpos de catedráticos de Bachillerato y Universidad comparecieron como subcampos docentes de atributos opuestos al anterior: sus miembros estuvieron mucho mejor retribuidos, poseían una formación más especializada, eran propietarios de un saber disciplinario exclusivo y ostentoso, y su tasa de feminización resultó nula hasta entrado el siglo XX y, en todo caso, escasa y tardía. Esta jerarquía docente reprodujo y plasmó la estructura de un sistema absolutamente dual que configuró el sistema de enseñanza del modo de educación tradicional-elitista: dos vías de escolarización (la primaria y la secundaria) independientes entre sí, que nunca se encontraron, que acogían a mundos sociales escindidos y que transmitían valores y conocimientos distintos. La imagen del buen maestro se oponía a la del buen catedrático.

Como decimos, esto fue radical y crudamente así durante todo el siglo XIX y, en sus rasgos fundamentales, permaneció hasta los años sesenta del XX y, cabría decir que, aún en nuestros días el pasado pesa y los códigos no escritos que rigen el habitus de los cuerpos \begin{tabular}{l|l} 
Revista RBBA & Revista Binacional Brasil Argentina
\end{tabular} 
docentes no son del todo ajenos a estas marcas primigenias. Con todo, durante las primeras seis décadas del siglo pasado, estas diferencias fueron amortiguándose levemente, al mismo tiempo que la lenta e incompleta expansión escolarizadora iba imponiendo nuevas formas. Grosso modo, el maestro tiende a funcionarizarse y a adquirir el ropaje de un saber más específico y reglado. De otra parte, los catedráticos iniciaron un tímido, pero imparable proceso de feminización en la educación secundaria, palpable ya en la década de los años 50, y los principios de legitimación en los que descansaba su status tradicional comenzaron a quebrarse (Cuesta y Mainer, 2015). Paralelamente, el discurso de la necesidad de la pedagogización del docente secundario comenzó a expandirse, a regularse en normativa efímera y de costosa y compleja aplicación y a materializarse en ciertos ensayos de corta vida y escasa ambición, tanto en el periodo republicano como en el franquista. Podría decirse que el advenimiento del modo de educación tecnocrático de masas - la extensión efectiva de la demanda de escolarización y, sobre todo, la interconexión de las dos vías existentes, primaria y secundaria, separadas hasta entonces - reportó una aparente aproximación de dos campos profesionales hasta entonces escindidos. El proceso culminó en la Ley General de Educación de 1970. Esta ley ensayó la profesionalización del magisterio elevando su formación a categoría universitaria y trató de generalizar condiciones de formación preprofesional pedagógica mediante la institucionalización del Curso de Aptitud Pedagógica (CAP) para los aspirantes a profesores de bachillerato.

La vigente legislación española sobre formación inicial supone de facto la profundización en unas reformas que, en puridad y como ocurre en muchos otros países, nunca triunfaron del todo. En efecto, esta pretendida impregnación pedagógica de la formación del profesor de secundaria, no ha supuesto que hayan desaparecido los resabios del pasado; por ejemplo, la identificación de las disciplinas científicas con la esencia del profesor de secundaria y de la pedagogía como saber específico y posesión distintiva del maestro. Entre las abundantes reformas del sistema educativo habidas en los últimos cuarenta años y el piélago de inercias y rutinas propias del campo profesional docente, los procesos de profesionalización y pedagogización han quedado muy lejos de los cambios habidos en la lógica de escolarización de masas. Baste recordar que, jurídicamente, el CAP se extinguió oficialmnete en 1995 y este zombi-difunto, tras suspensiones y resurrecciones sucesivas, como la de Lázaro, subsistió, con más pena que gloria, hasta bien entrado el siglo XXI; hasta \begin{tabular}{l|l} 
Revista RBBA & Revista Binacional Brasil Argentina
\end{tabular} 
LA PROFESIONALIZACIÓN DOCENTE EN PERSPECTIVA CRÍTICO-

GENEALÓGICA. EL CASO ESPAÑOL

que la Dirección General de Universidades estableció el curso 2008-09 como el último en que pudo impartirse legalmente. Por la misma ruta de la pedagogización y profesionalización, tras no pocos balbuceos e infaustos ensayos, ha transitado el acceso, mediante concursooposición, a la condición docente del secundario. Asimismo, pedagogización y profesionalización, dentro de la rampante racionalidad técnico-burocrática, constituyen, en efecto, el rumbo que orienta y gobierna la nueva producción de normativa universitaria, inspirada en los dictados del llamado Espacio de Educación Superior Europea (más conocido por "Declaración de Bolonia") de 1999.

\section{Algo más sobre el falso dilema ciencia versus pedagogia}

De lo anterior se deduce que, en buena medida, las nuevas leyes y reformas educativas de neta impronta tecno-burocrática y neoliberal que han venido afectando a la formación inicial y el acceso del profesorado ${ }^{\mathrm{v}}$ se presentan con el propósito de remozar un modelo ya obsoleto, siempre con la mirada puesta en incrementar en ambas la dimensión psicopedagógica del oficio docente. Un empeño que, como se verá, ha desatado no pocos conflictos y tensiones entre las facultades de psicología y educación y todas las demás, en particular a la hora de planificar los estudios del nuevo y obligatorio Master de secundaria (vigente desde 2011) y repartir el siempre sabroso, aunque amargo y cansino, pastel de la docencia en momentos de precariedad y libre concurrencia como los que atraviesa el espacio universitario. Lo cierto es que las facultades de educación se han visto beneficiadas en este proceso de pedagogización "a la boloñesa" (apelativo con que hacemos irónica referencia a la citada Declaración de Bolonia) pues no sólo han conocido la equiparación de su grado de maestro al de las demás carreras de cuatro años de duración, sino que se les ha otorgado una posición relevante en la organización, gestión y docencia del nuevo Master se secundaria por más que la casuística en relación con este asunto haya resultado finalmente muy diversa según el resultado de las complejas "negociaciones" llevadas a cabo en cada Universidad-. En efecto, de un tiempo a esta parte ha vuelto a abrirse la caja de los truenos en torno a la construcción del oficio de enseñar, al desatarse la consiguiente batalla por el "conocimiento", esto es, la lucha encarnizada entre las tribus académicas por conquistar el territorio de los nuevos grados, maestrías y doctorados. En la superficie de estas sordas luchas por el poder, el subterfugio utilizado sobre el que parece discutirse no es otro que el viejo dilema entre ciencia y pedagogía (Mateos, 2014). Una valetudinaria contraposición que se erigió, como ya hemos

Revista RBBA Revista Binacional Brasil Argentina 
dicho, con la construcción del sistema nacional y dual de enseñanza y que tantas apariencias ha adoptado desde hace más de un siglo contribuyendo al sustento de falsos problemas y que resurge ahora ofreciendo, además, un fácil argumentario a mayor gloria de los ranking de audiencia de los medios de comunicación. Pero no nos engañemos: cuando se discute acerca de la profesión y de los saberes que son o debieran ser inherentes a los docentes, se está hablando de mucho más que eso... En el fondo se está dirimiendo, nada más y nada menos, sobre la reproducción social y cultural que maestros y profesores secundarios desempeñan administrando y distribuyendo un conocimiento que se pretende extender y, al mismo tiempo, restringir. Una función paradójica si se quiere pero que, sin embargo, constituye el auténtico motor, la razón de ser que otorga sentido a la escolarización de infancia y juventud en la sociedad capitalista: la escisión entre la voluntad de enseñar — extender la cultura- y la necesidad de seleccionar — restringir la cultura—.

He aquí el significado profundo de la pervivencia de dos culturas y campos profesionales, la del maestro y la del secundario, que, pese a los cambios experimentados, permanecen aún profundamente arraigadas en las entrañas del sistema; las reglas implícitas y explícitas de ambas categorías docentes, así como el grado de profesionalización, prestigio y tipo de formación recibida permanecen en gran parte escindidas.

El hecho de que, con la vigente normativa, el maestro o la maestra primaria en España, superados los cuatro años de formación en el grado, pueda acceder directamente a la docencia, mediante concurso-oposición, sin la necesidad de cursar el Master, acorta en un año la preparación del primario reproduciendo su inferior estatus, en términos de acreditación burocrática, respecto al profesor de secundaria, para quien la obtención del título de Master constituye requisito sine qua non para opositar a la función pública. El peso de la historia pesa en el presente en orden a mantener la estructura jerárquica de los cuerpos docentes. A este respecto, llama la atención, aunque no sorprende, que entre el magisterio y, más concretamente, entre los actuales estudiantes del grado, no se levantaran voces reivindicando el cuerpo único de docentes al calor de esta reformista coyuntura universitaria. De todas formas, haciendo un poco de memoria sobre los avatares de tan popular demanda desde el final de la dictadura franquista, no se puede olvidar que la idea no surgió precisamente, a mediados de los años setenta del pasado siglo, de la "gran masa" de maestros, sino de los colegios de licenciados y de sus "alternativas democráticas" y, eso sí, de una minoría muy 


\section{GENEALÓGICA. EL CASO ESPAÑOL}

activa del magisterio que participaba en la vanguardia pedagógica. El magisterio se ha adaptado desde que se define como cuerpo nacional de funcionarios a una posición subordinada, reclamando mejoras salariales y laborales, atención social y "dignificación", pero dentro de su particular habitus profesional, sin plantar cara con decisión y menos con persistencia a la tradicional distancia y segregación respecto a los docentes de enseñanzas medias. De hecho, los sindicatos docentes, que en algún momento defendieron el cuerpo único dejaron de hacerlo porque, sin duda, la base sindical de los maestros nunca tuvo fuerza (sí número) y, tal vez, ni siquiera interés en ello.

\section{El Master de Secundaria español: la ceremonia meritocrática y la programación de la ignorancia.}

La formación inicial y permanente del profesorado ha sufrido en los últimos quince años un vertiginoso e irreversible proceso de mercantilización, privatización e insolvencia intelectual. Quien haya tenido ocasión de conocer de visu los abultados expedientes con que los aspirantes a ingresar en el Cuerpo de Profesores de Secundaria comparecen a los procesos de concurso-oposición españoles, inopinadamente poblados de documentos que certifican centenares de horas — digo bien: iicientos!! - dedicadas a las mayores zanganadas que puedan imaginarse —ursos de neuroeducación, competencias emocionales, coach, mindfulness, gamificación...- - y que se hacen pasar como horas de "formación", sabrá de lo que estamos hablando. La Declaración de Bolonia y las subsecuentes políticas de formación del profesorado en la Unión Europea pivotan sobre la idea de un docente dúctil y flexible como el sujeto del aprendizaje constructivista - adornado de múltiples "competencias" que han de conseguirse e incrementarse mediante un proceso inacabable de aprendizaje sin fin, muy a tono con las formas de organización del trabajo postfordistas y que se corresponden con una suerte de programación de la ignorancia que, como en el mito de Sísifo, permite legitimar la falacia del lifelong learning. En este marco, la evaluación continua de las competencias y de los hipotéticos resultados de la acción docente se convierten en la clave de todo el nuevo sistema. Se impone una lógica importada de la gestión empresarial accountability, en su bárbara formulación - y se entroniza un modelo de evaluación como dispositivo de medición de la productividad del trabajo y del rendimiento de los recursos empleados. Es, en realidad, otro modo de dominación que sustituye la lógica taylorista por \begin{tabular}{l|l} 
Revista RBBA & Revista Binacional Brasil Argentina
\end{tabular} 
una forma más sutil y perversa de explotación del trabajo. Todo ello en consonancia con las formas más refinadas de legitimación y autosometimiento inherentes al modo de educación tecnocrático de masas y a las sociedades de control del totalcapitalismo de nuestro tiempo.

El nuevo marco de estudios superiores impuesto en Europa, siguiendo fielmente el canon estadounidense, ha supuesto el paso más alto, hasta ahora, dentro de la extensión de la racionalidad instrumental que guía el desarrollo del modo de educación tecnocrático de masas. En la práctica, ha significado, a poco que nos fijemos, trasladar hacia arriba el tecnicismo psicopedagógico y la burocratización que comenzó a desparramarse por la educación primaria y secundaria españolas de la mano del ciclo reformista que tuvo lugar entre los años 70 al 90 del siglo XX — procesos muy semejantes se produjeron en la mayoría de los países latinoamericanos- Como ocurrió en la educación secundaria española durante los años noventa, el proceso de pedagogización "a la boloñesa" no ha sido ajeno a la progresiva infantilización de los campus universitarios, a un incremento de las tensiones y conflictos entre saberes-poderes (que ya emergió, como hemos dicho, en la discusión de los planes de estudio de los nuevos grados y volvió a reproducirse con la implantación de masteres y doctorados), y a la victoria pírrica de una cierta revolución terminológica (como, en realidad, es la de las "competencias") junto a la escandalosa permanencia de los vetustos usos de siempre (incluidas las prácticas endogámicas que han seguido siendo privativas en la cooptación de sus docentes).

El Master de Secundaria es un fiel exponente de cuanto estamos afirmando. La sola contemplación del plan de estudios del que se cursa, por ejemplo, en la Universidad de Zaragoza — informado positivamente por la Agencia Nacional de Evaluación de la Calidad y Acreditación (ANECA) en 2009 y revalidado en 2015-, deja bien a las claras el menú, ciertamente ayuno de proteina y masa crítica, que se supone debe poseer un graduado que tenga intención de ingresar en el cuerpo de profesorado de secundaria. Veamos: el peso fundamental de las materias obligatorias (36 de los 60 créditos prescritos) se refiere a conocimientos de legislación educativa, organización escolar y sistemas de evaluación, otorgando un escasísimo peso a las didácticas especiales y nulo a la historia del currículum o de la educación en su conjunto. Si atendemos a su desarrollo y a la vista de lo sucedido en estos años de vigencia, es vox populi que el nuevo curso ha supuesto el encarecimiento inopinado de una formación ya de por sí devaluada; una nueva barrera burocrática y 
LA PROFESIONALIZACIÓN DOCENTE EN PERSPECTIVA CRÍTICO-

\section{GENEALÓGICA. EL CASO ESPAÑOL}

económica que no se justifica ni por su contenido ni por criterio de rentabilidad alguno. Por otra parte el curso se ha venido desarrollando merced a una notable improvisación tanto en los aspectos organizativos como en los docentes y curriculares; se ha manifestado una importante carencia de personal docente idóneo, seleccionado con criterios de escaso horizonte intelectual y a menudo desperdiciando los recursos disponibles. Por último, cabe añadir que la pedagogogización "a la boloñesa" ha impregnado en este caso la aplicación de una formación que ha retomado los prejuicios más escandolosos del idealismo pedagógico, que habían presidido las reformas educativas en primaria y secundaria, trasladándolos sin más a la universidad donde, en realidad, se ha de formar a una legión de profesionales desprovistos de autonomía profesional y de pensamiento crítico.

Por lo que hace al procedimiento de acceso a los cuerpos docentes, no se ha modificado el sistema de concurso-oposición, vigente sin apenas cambios desde hace casi medio siglo. $\mathrm{Y}$, pese a los sucesivos anuncios y renuncios, no parece que el procedimiento vaya a transformarse sustancialmente. Sí cabe pensar que las oposiciones de Secundaria sufran alguna mutación temática a favor de un diseño más pedagógico y más en congruencia con los conocimientos supuestamente adquiridos en el Master, sobre todo si la roma doxa neotecnicista y transposicionista de las emergentes didácticas específicas termina por colonizar, como pretende y parece, el grueso de los contenidos de aquél.

En lo que respecta la formación permanente del profesorado ya en activo, nada permite pensar en la sustitución de los llamados "centros de profesores" creados en la década de los años ochenta y diseminados por todo el territorio español. Su más que relevante papel en la mercantilización y privatización endógena de la escuela pública al convertirse en el mayor adalid de la venta y promoción de todo tipo de "programas y proyectos de innovación" y de entronización de nuevas tecnologías — tras la que existe, por cierto, un sustancioso negocio-, los hacen imprescindibles aliados y reproductores de las políticas neoliberales. De hecho, en España, han jugado un papel estelar a la hora de distinguir y personalizar a los centros docentes inmersos en una absurda y perversa carrera para atraer clientes y colocarse por delante de quien sea y a costa de lo que sea - pantallas digitales, ipod, y demás mercachiflería tecnológica, bilingüismo, instrucción financiera, programas de emprenduría, mindfulness aplicado a la educación, inclusividad, educación emocional..., todo vale en la carrera de la banalidad- - .

Revista RBBA $\mid$ Revista Binacional Brasil Argentina 
Cada vez más, formarse como profesor hoy en España es, ante todo, una inversión económica. Los profesores seguimos siendo, como antaño, "guardianes de la tradición y esclavos de la rutina", pero ahora, por todos los medios, se intenta que además seamos "esclavos de la innovación"; como decía un viejo camarada "fedicariano", la educación, como la democracia, al fin encontró a su pareja: el mercado (Rozada, 2002). En este contexto de vulgar frivolidad mercantil, se ha venido desarrollando en España el espectáculo de docentes innovadoras convertidos súbitamente en personajes mediáticos, que cual férvidos predicadores de la innovación psicopedagógica pululan en los medios y en las "redes sociales", financiados por fundaciones (supuestamente sin ánimo de lucro) como Ashoka, Junior Achievement o Gems Education y que en realidad son pantallas de poderosos lobbies empresariales y financieros (BBVA, Telefónica, La Caixa, Banco de Santander, Inditex, Mapfre, JP Morgan, Bertelsmann...), con el apoyo de gobiernos de casi todo el arco parlamentario, hacen su agosto a costa de la educación pública. La sociedad del espectáculo, el filantrocapitalismo y la mercantilización de la educación pública encuentran así un nicho de negocio suculento que se legitima en aras de la profesionalización docente.

Por tanto, las perspectivas de formación del profesorado se han hecho más complejas y burocráticas, dentro de una razón mercantil, tecnicista y pscio-pedagógica que todo lo arrasa. Es un hecho que toda esta faramalla legislativa avanza a favor de la tecnocracia y, sobre todo, de un control más difuso pero no menos severo y riguroso de la capacidad autoformativa de los docentes, lo que implica una profunda desprofesionalización y una reducción de los espacios laborales e institucionales para el ejercicio de una labor realmente crítica. Por eso hoy, más que nunca, es necesario encontrar y defender espacios de resistencia y formación crítica autogestionados ante una avalancha normativa que, envuelta en el papel regalo de las competencias y otros embelecos, en realidad únicamente busca cerrar el paso a los procesos de formación autónoma y contrahegemónica de los docentes. La formación de los y las docentes debe seguir siendo, también, un campo de resistencia y de lucha contra el totalcapitalismo y las políticas educativas del neoliberalismo global. 


\section{LA PROFESIONALIZACIÓN DOCENTE EN PERSPECTIVA CRÍTICO- GENEALÓGICA. EL CASO ESPAÑOL}

\section{REFERENCIAS}

CUESTA, R. Sociogénesis de una disciplina escolar: la Historia. Barcelona: Pomares Corredor, 1997.

CUESTA, R. y MAINER, J. "Guardianes de la tradición y esclavos de la rutina: historia del campo profesional de los catedráticos de Instituto", Historia y Memoria de la Educación, 1, 351-393, 2015.

CUESTA, R.; MAINER J.; y MATEOS J. coords. Transiciones, cambios y periodizaciones en la historia de la educación. Salamanca: Lulú ediciones, 2009.

CUESTA, R.; MAINER, J.; MATEOS, J.; MERCHÁN J.; y VICENTE M. "Didáctica crítica. Allí donde se encuentran la necesidad y el deseo", en ConCiencia Social, 9, 17-54, 2005.

LERENA, Carlos. Reprimir y liberar. Crítica sociológica de la educación y de la cultura contemporáneas. Madrid: Akal, 1983.

LERENA, Carlos Escuela, ideología y clases sociales en España. Barcelona: Ariel, 1986.

MAINER, Juan. La forja de un campo profesional. Pedagogía y didáctica de las ciencias sociales en España, 1900-1970, Madrid: CSIC, 2009.

- "Claves sociogenéticas del campo científico de la Pedagogía en España", en T. Rabazas (coord.) Evolución y consolidación del conocimiento teórico de la educación en España, Madrid: Síntesis, 2014.

MATEOS, Julio. "Pedagogía: ¿arte o ciencia? Un viejo debate inacabado", en J. L. Hernández Huerta y otros (coords.), Educación y Utopía. Ensayos y estudios, Salamanca: Fahren House, 15-35, 2014.

ROZADA, José Ma . "Las reformas y lo que está pasando. (De cómo en la educación, la democracia encontró su pareja: el mercado)". ConCiencia Social, 6, 15-58, 2002.

\section{Notas}

\footnotetext{
i Versión muy semejante del presente texto fue publicada con el título "El sujeto docente y su construcción. Aproximación socio-histórica a la formación del profesorado desde el presente" en la revista digital Forum Aragón, 23, 2018, 19-26.

ii Personalmente, me he ocupado de estos temas en Mainer (2009) y Mainer (2014).

iii El término Didáctica Crítica refiere a un concepto acuñado en el espacio de la Federación Icaria (Fedicaria), plataforma de pensamiento crítico constituida hacia 1996, que edita la revista ConCiencia Social. La Didáctica Crítica, inseparable de una crítica de la pedagogía y la didáctica académicas actualmente hegemónicas, es una
} 
actividad teórico-práctica (pensamiento y acción) que teniendo por objeto la explicación y reorientación de lo que sucede en la escuela del capitalismo, se ejercita en el espacio público escolar, desde un lugar suprainstitucional y extraoficial, contra el mercado y contra el Estado, y al servicio de ideas que anticipan una sociedad que impugna la existente. La Didáctica Crítica se funda en torno a tres vectores: la crítica de la cultura, el análisis histórico-genealógico y la defensa de formas alternativas de política de la cultura. Así pues, cultura, historia y política dibujan el trípode sobre el que se construyen los postulados o enunciados-guía que la informan y orientan: problematizar el presente, pensar históricamente, educar el deseo, aprender dialogando e impugnar los códigos pedagógicos y profesionales. Para profundizar en estas cuestiones puede consultarse, R. Cuesta, J. Mainer, J. Mateos, J. Merchán y M. Vicente (2005).

iv Modo de educación es una categoría o concepto heurístico construida originariamente por R. Cuesta (1997), que hemos venido utilizando en el curso de las investigaciones histórico-educativas desarrolladas en el marco del Proyecto Nebraska de Fedicaria (Cuesta, Mainer y Mateos, 2009). Al respecto puede consultarse el sitio web del propio Proyecto Nebraska <http://www.nebraskaria.es/>.

v Una proliferación normativa que en España comenzó en 2005 con la regulación de los Estudios de Grado y Postgrado; continuó con la Ley Orgánica de la Educación (LOE) de 2006 — sustituida por su prima hermana, la vigente y contestada Ley Orgánica de Mejora de la Calidad Educativa (LOMCE) de 2013 - y la Ley Orgánica de Universidades (2007), y culminó, por ahora, con la súbita regulación del Master de Secundaria vigente desde 2011.

\section{Sobre el autor}

Juan Mainer Baqué es Doctor en Historia Contemporánea por la Universidad de Zaragoza (España); Especialista en Historia de la Educación y miembro de la Federación "Icaria" (Fedicaria).

Dirección electrónica: juanmainer@gmail.com 